\title{
Closure of Tailings Impoundments — Chilean Experiences
}

\author{
S. Dal Pozzo Golder Associates S.A., Chile \\ C. Andrade Golder Associates S.A., Chile
}

J.A. Wates Golder Associates Africa (Pty) Ltd, South Africa

B.J. Griffin Golder Associates Ltd, Canada

\section{INTRODUCTION}

Although Chile has been a mining country for over three hundred years, it does not have specific laws and regulations on mine closure. Currently, there is awareness of the necessity to establish a technical-legal framework for both the mining companies and the regulatory authorities.

This paper describes the present situation relating to mine closure in Chile and in particular to the closure of tailings impoundments. The advantages of using a risk based methodology to develop closure plans are discussed and in this way, the key aspects of the required actions for closure of tailings impoundments are identified.

The recommendations for revision of the current mine closure regulatory regime has been developed through a review of the current legislation and laws that are presently under development in the country.

\section{TAILINGS IMPOUNDMENTS - CURRENT SITUATION IN CHILE}

\subsection{Mining - Current Situation in Chile}

Mining is the most important economic activity in Chile and it produces $52.8 \%$ of the country's total exports by value. Of this, $85.6 \%$ is from copper mining which has experienced a $7.6 \%$ average growth rate per year since 1995.

Small, medium and large mining companies have been differentiated in Chile, according to the size of the labour force employed. Large companies have more than 400 workers and small companies, less than 80 workers employed.

According to this classification, copper production can be categorized as follows:

Table 1 Copper production in Chile in 2004

\begin{tabular}{|l|c|c|}
\hline Company Size & $\begin{array}{c}\text { Total Copper Production } \\
\text { (million ton/annum) }\end{array}$ & $\begin{array}{c}\text { Copper Produced by Flotation } \\
\text { (million ton /annum) }\end{array}$ \\
\hline Large companies & 5.00 & 3.79 \\
\hline Medium companies & 0.36 & $0.20\left(^{*}\right)$ \\
\hline Small companies & 0.06 & $0.04\left(^{*}\right)$ \\
\hline Total & $\mathbf{5 . 4 2}$ & $\mathbf{4 . 0 3}$ \\
\hline
\end{tabular}

$(*)$ Estimated values 


\subsection{Tailings Impoundments - Current Situation}

Surveys conducted by the SERNAGEOMIN ${ }^{1}$ in 1996, identified more than 900 tailings impoundments that were either under development, in operation or abandoned. There are no precise records on the dimensions of the impoundments or of the segment they are associated with; however, it can be inferred that a significant proportion of these are small tailings impoundments related to small size mining operations. Many of these are abandoned without planning or control and, therefore small mines are responsible for most of the abandoned tailings facilities.

The SERNAGEOMIN surveys report that medium sized mines are responsible for about 30 tailings storage facilities either under development, in operation or abandoned.

As most of the tailings are generated in arid zones, evaporation is high and the risk of contaminating underground water by seepage is limited. Dust emitted from dry facilities is however a concern. Most abandoned dams have not been managed well and some of them have either failed or have been damaged by wind and water erosion due to a number of factors. Such as poor surface water management, liquefaction under seismic loads, insufficient drainage in the basin etc.

Most large mines have been developed over the last 20 years and are still operating. Table 2 shows a list of the main tailings facilities and their current situation.

Table 2 Large tailings facilities in $\mathrm{Chile}^{2}$

\begin{tabular}{|l|l|l|l|}
\hline No. & \multicolumn{1}{|c|}{ Owner } & \multicolumn{1}{|c|}{ Dam Name } & \multicolumn{1}{|c|}{ Current Situation } \\
\hline 1 & $\begin{array}{l}\text { Collahuasi } \\
\text { (Anglo American, Falconbridge, } \\
\text { Mitsui) }\end{array}$ & Pampa Pabellón & Operating \\
\hline 2 & $\begin{array}{l}\text { Escondida } \\
\text { (BHP Billiton, Rio Tinto, IFC, Jeco) }\end{array}$ & $\begin{array}{l}\text { Hamburgo } \\
\text { Laguna Seca }\end{array}$ & $\begin{array}{l}\text { Post operation } \\
\text { Operating }\end{array}$ \\
\hline 3 & Candelaria (Phelps Dodge, Sumitomo) & Candelaria & Operating \\
\hline 4 & $\begin{array}{l}\text { Los Pelambres } \\
\text { Antofagasta Minerals, Nippon LP } \\
\text { Inv., MM LP Holding BV) }\end{array}$ & $\begin{array}{l}\text { El Chinche } \\
\text { Quillayes } \\
\text { Mauro }\end{array}$ & $\begin{array}{l}\text { Post operation } \\
\text { Operating } \\
\text { Under construction }\end{array}$ \\
\hline 5 & $\begin{array}{l}\text { Minera Sur Andes } \\
\text { (Anglo American) }\end{array}$ & $\begin{array}{l}\text { El Cobre No.1 } \\
\text { El Cobre No.4 } \\
\text { El Torito } \\
\text { Pérez Caldera No.1 y No.2 }\end{array}$ & $\begin{array}{l}\text { Post operation - removing } \\
\text { tailings to Las Tórtolas } \\
\text { Operating }\end{array}$ \\
\hline
\end{tabular}

\footnotetext{
${ }^{1}$ SERNAGEOMIN: Chilean Regulatory Agency for Geology and Mining.

${ }^{2}$ Public Domain Information contained in Chilean Mining Compendium 2006
} 


\begin{tabular}{|c|c|c|c|}
\hline No. & Owner & Dam Name & Current Situation \\
\hline 6 & $\begin{array}{l}\text { Codelco Chile - División Codelco } \\
\text { Norte }\end{array}$ & Talabre & Operating \\
\hline 7 & Codelco Chile - División Salvador & Austral & Operating \\
\hline 8 & Codelco Chile - División Andina & $\begin{array}{l}\text { Ovejería } \\
\text { Piuquenes No.1 } \\
\text { Los Leones }\end{array}$ & $\begin{array}{l}\text { Operating } \\
\text { Post operation } \\
\text { Post operation }\end{array}$ \\
\hline 9 & Codelco Chile - División El Teniente & $\begin{array}{l}\text { Carén } \\
\text { Cauquenes } \\
\text { Barahona } \\
\text { Colihues }\end{array}$ & $\begin{array}{l}\text { Operating } \\
\text { Post operation } \\
\text { Post operation } \\
\text { Post operation }\end{array}$ \\
\hline 10 & Compañía Minera El Indio (Barrick) & El Indio & Closed \\
\hline 11 & Ojos del Salado (Phelps Dodge) & Tranque No. 8 & $\begin{array}{l}\text { Closed - covered by a } \\
\text { waste dump }\end{array}$ \\
\hline
\end{tabular}

A review of 25 large mine tailings impoundments indicates that, only one is in a formal closed state, two have been absorbed by other mining operations, two are being removed, eight have been decommissioned, one has failed, one is currently under construction and ten are presently operating. All tailings facilities that have been decommissioned require a closure plan in the short term, while those facilities in operation or under construction require a closure plan in the medium or long term.

\section{CURRENT CHILEAN LAW}

\subsection{Effective Regulations}

Presently, Chile does not have a regulatory structure to specifically control the closure of mines.

However, there are laws that indirectly control mine closure. These are:

- Decreto Supremo, D.S. No.132 - Mining Safety Regulation - of the Mining Ministry.

- Law No.19.300 General Basis of the Environment.

In addition, there are a number of complementary regulations related to aspects of tailings facility closure:

- D.S. No.90/01, Standard for Emission of Contaminants Associated to the Liquid Waste Discharge to Oceans and Continental Waters.

- D.S. No.59, Standard for Primary Quality of Particulate Material Emission.

The D.S. No.132 provides a definition of a Closure Plan and its objectives. Closure Plans are required to contain measures to prevent, minimize and/or control the risks and negative effects that might arise or persist once the mining operations have ceased. The measures included in closure plans should consider the particular circumstances of the location and environment. For the closure stage of tailings impoundments, facility dismantling, fresh water source maintenance, diversion channels maintenance, surface water management, access control, basin and slope cover, signage, emergency waste dump development, decant tower closure fencing, wind screening, embankment crest berm compaction, emergency ponding and management, and protection of the embankment toe are required to be considered. 
The D.S. No. 132 regulation is prescriptive in the requirements for closure and does not provide for flexibility. This approach could lead to an overly conservative and expensive Closure Plan, while not necessarily achieving the desired objectives. A better approach would be a risk approach based on monitoring of the main time dependent variables of concern to demonstrate that closure objectives are being met. This will provide mining companies with flexibility to implement more efficient and appropriate measures and to demonstrate compliance through monitoring thereby allowing a more efficient use of resources.

Law No. 19.300 states that mining projects, including oil, coal and gas projects, must undertake an Environment Impact Assessment (SEIA). This can be done through either an Environmental Impact Declaration (DIA) or an Environmental Impact Study (EIA), depending on which of the effects, circumstances or characteristics defined in the Law are expected. It is implicit that the closure phase for these projects should form part of the assessment submitted for approval.

\subsection{Draft Law}

A new draft law to regulate mine closure is presently under development. This law aims to consolidate all regulations under the same structure, and implement technical, economical and legal guidelines for the mining companies and regulatory authorities.

The draft law establishes a legal obligation for mining companies to submit a Closure Plan for its facilities for approval to the SERNAGEOMIN. The objective of the Closure Plan is to prevent, minimize and/or control the risks and adverse effects arising from or persisting during the post-closure stage, as they apply to people's health and safety and/or the environment. Different requirements and procedures are prescribed depending on the mine size. Thus a simplified procedure is available, with less stringent requirement, for mines with production levels of less than $5000 \mathrm{t}$ per month.

According to the law, the technical aspects which have to be considered by mines with production rates over 5000 tons per month, are: projection of the mining operations, the time period for closure, projection of the environmental impacts within the influence area, proposed closure actions with associated costs and schedules, a follow up plan for the relevant environmental variables, a community information program on the Closure Plan implementation and the economic guarantee to be used. This Closure Plan should be periodically audited.

The mines must submit a Final Audit Report once all the Closure Plan activities, which have been committed to, have been fully implemented. SERNAGEOMIN will review and approve this report. SERNAGEOMIN will then issue a Closure Plan Compliance Certificate, once the legal and regulatory commitments and obligations have been met. This Compliance Certificate will certify the full and timely compliance of the duties and obligations arising from the application of this law, notwithstanding the liabilities that other legal regulations may impose.

For mining operations with production rates of less than $5000 \mathrm{t}$ per month, the SERNAGEOMIN will provide method based guidelines or standards for the Closure Plan.

\section{$4 \quad$ APPLICATION OF RISK ANALYSIS IN CLOSURE STUDIES}

Alternative methods to develop closure plans issues include:

- Mitigation in accordance with a prescribed standard for potential impacts.

- Mitigation in accordance with a site specific risk assessment.

Risk assessment is a more objective approach to prioritize the use of resources based on a risk measure that includes both the probability and severity of potential consequences.

Risk assessment can be used to prioritize all identified hazard scenarios and then to apply appropriate mitigation measures, focusing on the high priority risks. Thus, mitigation measures are applied where they are of most benefit, for the high priority risks and are restricted where benefits are limited for the low priority risks. The mitigation measures can be optimized to address the probability, the severity of consequences or a combination of both components of risk. 
The risk assessment approach enables both the public and private sectors to prioritize investment and/or actions at a project's closure stage.

\section{IDENTIFICATION OF THE KEY ASPECTS IN THE TAILINGS IMPOUNDMENT CLOSURE STAGE}

To identify the key aspects at the tailings impoundments closure stage, it is necessary to identify the origin, cause and effect of the events that might represent a risk for:

- People.

- Environment.

- Economic activities.

Firstly, it is necessary to identify the risk scenarios, their probability of occurrence and the consequence of the occurrence. This is achieved through characterization and understanding of the project area and related facilities. For the project area, it is necessary to be familiar with:

- The morphology.

- The geology and geotechnics.

- Seismicity.

- Hydrometeorology.

- Existing economic activities.

- Population.

- Characteristics of the environment.

- Waterflows.

For tailings impoundments, the characteristics listed above will influence the following aspects that should all be analyzed and, if necessary, mitigated at the closure stage:

- Physical stability.

- Infiltration.

- Dust generation.

- Acid generation and drainage.

- Visual degradation.

- Possible interception of natural water flows (usage could be restricted for the development of economic activities and/or human utilisation).

In order to validate the design of the mitigation measures, the following activities must be undertaken:

- Monitor the variables of concern to evaluate their performance through time and decide if a mitigation measure is necessary and determine up to what level to mitigate.

- Evaluate the probability of occurrence and consequences associated with each source of risk to prioritize risks and focus on the mitigation of the higher risks.

- Analyze the impacts that might be produced in other dimensions of the environment (e.g. social or economic). For example the consequences that could result from the decision to cover the facility basin with granular material from a borrow source outside the basin may impact adversely on another land use such as agriculture. 


\section{ECONOMIC GUARANTEES}

At present, a legal requirement for the provision of economic guarantees that can be called upon to effect closure does not exist in Chile.

There is a law that applies in some instances where the Water Code (DFL-1122), implemented by the General Waters Directorate ${ }^{3}$ (DGA), which stipulates economic guarantees for some hydraulic facilities, so as to provide financial support in case of an eventual modification, dismantling, or if abandoned during its construction is applicable. The Law states that the guarantee must be issued in favour of the Treasury Administration and will be released once the works have been completed to the satisfaction of the DGA. The Code covers water dams with a capacity over $50000 \mathrm{~m}^{3}$ or dams whose wall is higher than $5 \mathrm{~m}$; aqueducts conducting more than $2 \mathrm{~m}^{3} / \mathrm{s}$ or more than $0.5 \mathrm{~m}^{3} / \mathrm{s}$, in case they are close to urban zones and siphons and ducts crossing natural water flows. The objective of the guarantee is to assure the implementation of the safety measures and/or the construction of the required works related to physical stability of the structures.

Tailings impoundments are construed to fall within the ambit of the Water Code and therefore this economic guarantee is required by DGA for the different stages of the impoundments useful life.

In the proposed law for mine closure, economic guarantees are required to cover the cost of implementation of the closure plans of mining operation with production levels over $5000 \mathrm{t}$ per month. The guarantee is required to assure the State of the availability of the necessary funds to cover the cost of outstanding work in the event that the company fails to comply with the obligations of the regulation.

This law prescribes that the amount of the guarantee shall be determined based on the calculated costs of the full and complete implementation of the Closure Plan.

Different types of financial instrument to set the economic guarantee are contemplated including cash, letters of credit issued by financial institutions; titles guaranteed by financial institutions; term deposits, bonds and others, issued by financial institutions; titles issued by the General Treasury of the Republic or the Central Bank of Chile and bonds from public or private companies. The guarantee instruments shall be lodged with an institution supervised by the Superintendencia de Valores y Seguros (Superintendence of Financial Values and Insurances.

One of the aspects not being considered by the proposed law, which is considered to be important when establishing the economic guarantee amount, is the criteria or methodology to be used in the closure cost estimation. This is important since most mining projects have a useful life over 25 years and it is necessary to assure that the estimated amounts cover the costs of the required and committed activities a long time in the future. The cost of closure also depends on when the estimate is done over the mine life. Figure 1 provides a typical evolution closure cost liability for a mining operation.

Figure 1 shows how costs increase rapidly during the project construction phase and how these costs can tend to a constant value if measures of progressive closure begin to be implemented concurrently during the project operation. Depending on the individual characteristics of the mine and its environmental setting, funds might be required to cover maintenance programs for extended periods. These costs can be difficult to estimate.

\footnotetext{
${ }^{3}$ The Water General Direction (DGA, Dirección General de Aguas) is an entity dependent of the Public Works Ministry.
} 


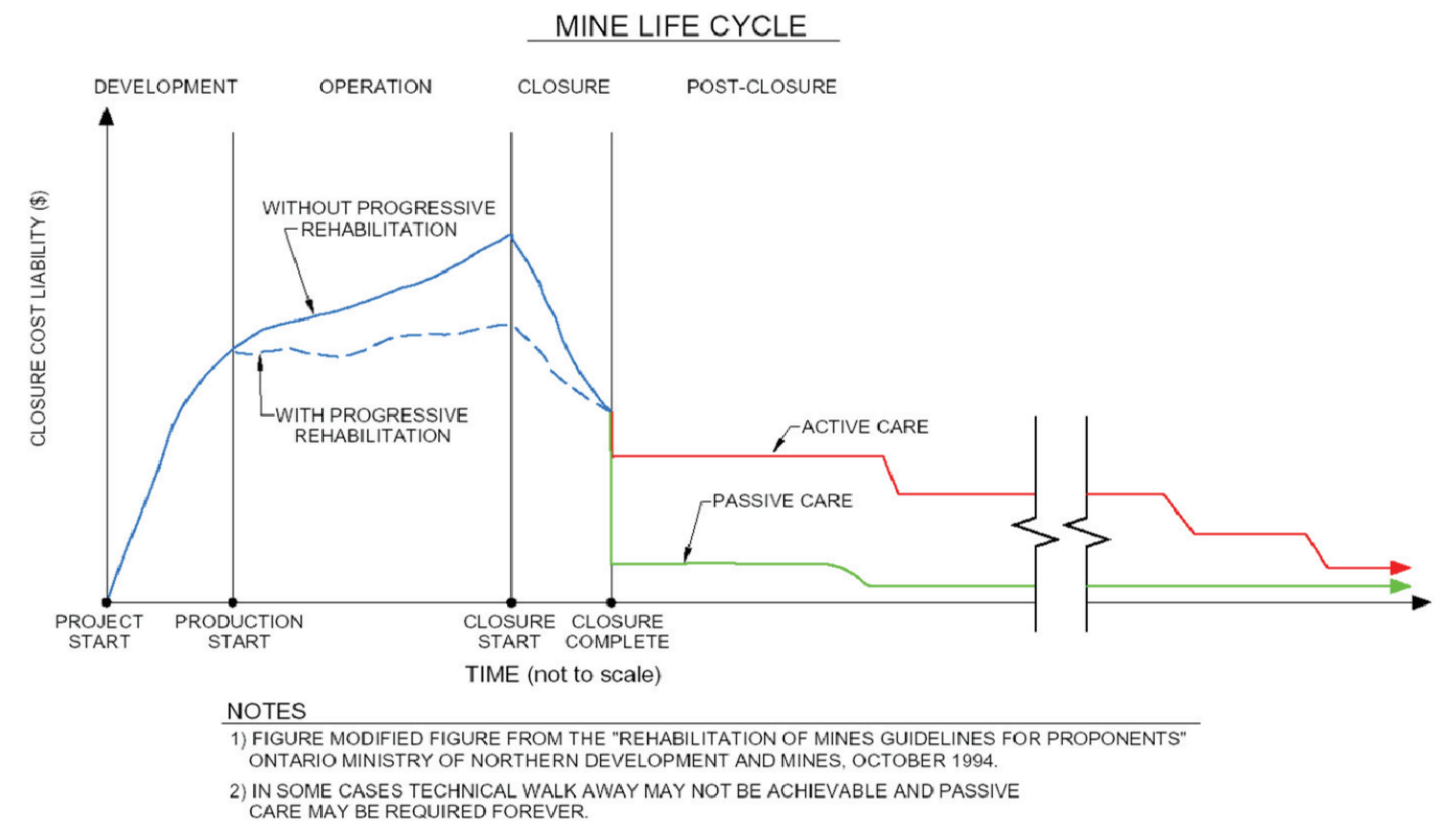

Figure 1 Cost curve for the closure plans

\section{$7 \quad$ CONCLUSIONS}

The different phases that constitute a mine activity could produce impacts that could affect people, the biophysical environment and /or economic activities. However, if the mitigation during the construction, operation and closure phases is based on technologically appropriate practices, it is possible to mitigate the adverse effects that the mine might generate and in this way to make a positive contribution to sustainable development.

In closure, it is important to add that there is always a post-closure residual risk, since it is neither economically viable nor efficient to design all the mitigation measures for the worst possible scenarios. A tool for setting risk priorities for more efficient resource assignment is risk assessment. This methodology widely is used worldwide.

Even though Chile is one of the main mining countries in the world, it still does not have a technical - legal regulatory regime for closure of mining operations. A new law is under development to provide a framework of the existing regulations. This law includes the economic guarantees to provide assurance that the closure plans proposed by the mining companies will be implemented even if the companies cease to exist. Cost estimation methodologies are not currently defined and will leave room for uncertainty when the new law is promulgated. This issue needs to be addressed to provide certainty. Guidelines should be provided for criteria for cost estimation to provide the State with confidence that the provisioned funds will cover the closure costs in the long term with a reasonable level of reliability.

\section{REFERENCES}

Ministry of Mining, Chile (2006) Preliminary Law for Mine Closure.

University of Chile, Department of Industrial Engineering (2001) Analysis of Mine Closure Plans.

Golder Associates (2004) Guideline document for the evaluation of the quantum of Closure - Related Financial Provision provided by a Mine.

Chilean National Committee on Large Dams, Large Dams in Chile, published during the 1996 ICOLD Conference Santiago, Chile (1996).

Public Domain Information contained in Chilean Mining Compendium 2006. 